\title{
Making a Third Space for Student Voices in Two Academic Libraries
}

\section{James Elmborg, Heidi LM Jacobs, Kelly McElroy, and Robert Nelson}

James Elmborg is Associate Professor
and past Director in the School of
Library and Information Science
at the University of lowa. Heidi LM
Jacobs (hjacobs@uwindsor.ca) is
an Information Literacy Librarian
at the University of Windsor's Leddy
Library. Kelly McElroy is the Student
Engagement and Community
Outreach Librarian at Oregon State
University. Robert L. Nelson is an
Associate Professor in the Department
of History at the University of
Windsor, Ontario, Canada.

Reference \& User Services Quarterly, vol. 55, no. 2, pp. 144-55

(c) 2015 American Library Association. All rights reserved.

Permission granted to reproduce for nonprofit, educational use.
When we think of voices in the library, we have tended to think of them as disruptive, something to control and manage for the sake of the total library environment. The stereotype of the shushing librarian pervades public perception, creating expectations about the kinds of spaces libraries want to create. Voices are not always disruptive, however. Indeed, developing an academic voice is one of the main challenges facing incoming university students, and libraries can play an important role in helping these students find their academic voices. Two initiatives at two different academic libraries are explored here: a Secrets Wall, where students are invited to write and share a secret during exam time while seeing, reading, commenting on the secrets of others; and a librarian and historian team-taught course called History on the Web, which brings together information literacy and the study of history in the digital age. This article examines both projects and considers how critical perspectives on voice and identity might guide our instructional practices, helping students to learn to write themselves into the university. Further, it describes how both the Secrets Wall and the History on the Web projects intentionally create a kind of "Third Space" designed specifically so students can enter it, negotiate with it, interrogate it, and eventually come to be part of it.
I n his landmark essay, "Inventing the University," David Bartholomae argues persuasively that "every time a student sits down to write for us, he [or she] has to invent the university for the occasion . . . to learn to speak our language, to speak as we do, to try on the peculiar ways that define the discourse of our community." Indeed, as Bartholomae goes on to claim, the student is immediately in a false position, implicitly claiming to be someone he or she is not by "faking" the academic voice. This predicament is doubly difficult for the student because this "voice" is not simply something to mimic. It is an entire identity. The academic voice is a voice of certainty, a knowing voice. To assume the academic voice, the student must pretend to know what academics know and to speak with mastery of the rhetorical and the analytic tools of the discipline within which they pretend to work, and they need to do so with confidence. This challenge becomes more difficult on a sliding scale based on how familiar students are with academic life and work. Students from nonacademic backgrounds are much less likely to be able to "fake" this voice than are those from homes and schools where Standard English is not the vernacular. 
Bartholomae's essay is an important statement in our efforts to understand how academic expectations structure academic writing. In this view of academic work, the student negotiates a writing product with certain characteristics that she thinks will meet her professor's expectations. In addition to voice, the student's writing must show organization, development (or logic), an appropriately sophisticated vocabulary, correct grammatical structures, and appropriate use of evidence. All these are wrapped up into what may be called academic "genres." Michelle Holschuh Simmons has discussed the role of academic genres in the work of what she calls "disciplinary discourse mediators." ${ }^{2}$ She suggests that as students learn to write and research in the academy, they often deal with professors so immersed in their advanced research work that they cannot provide the scaffolding students need to understand disciplinary conventions. She encourages librarians to take on the role of "mediator" between professors and students, to help them learn the expectations their professors have for them in terms of writing and research.

Our argument builds on these observations. Like literary genres, academic genres are advanced performances that depend on an understanding of audience and what they expect from a given written composition. The true challenge for the young writer lies in this set of expectations. The genre is not prescriptive. There is no set of rules a writer can follow to guarantee an acceptable writing product. There must be something more. The student can know the rules and still produce a bland and lifeless paper. The difference is located somewhere in the area of "voice." Voice is extremely difficult to quantify or describe, much less teach. A traditional view has located voice somewhere in the area of core identity, a place from which we speak that is our authentic and essential self. In the discussion that follows, we contest this perception of voice as "essential." We want to argue that, far from coming from an essential or core self, voice is constructed, reconstructed, and negotiated with other voices in the social world around us. We can and do learn new voices all the time as we negotiate with various discourse communities, and we adjust our voices as we move through our social worlds. In what follows, we will explore the pedagogical implications of two different libraries' efforts to help students develop a voice to communicate within the academy.

\section{JIM: VOICE AND SPACE}

The relationship between voice and self has been the object of much discussion among educational theorists. Our perspective is heavily influenced by Lev Vygotsky who saw language development as primarily social, something negotiated between those who speak and the other speakers in the world around them. ${ }^{3}$ As small children, we learn to speak by imitating others. Our words, phrases, and the ranges of meaning come from the verbal environment of those closest to us. As we grow and mature, we move toward self-containment in our speech, and voice becomes a primary aspect of our identities, but one that still always exists in the process of negotiation with the outside world. ${ }^{4}$ Mikhail Bakhtin, another influential theorist in our understanding of language and voice, studied Russian novels, especially those of Fyodor Dostoevsky. ${ }^{5}$ Bakhtin observed that novels tend to exist on a continuum related to voice. On one extreme, which he termed "monologic," the narrator's voice dominates the narrative. All the voices sound the same, like the voice of the narrator. On the other end of the spectrum, which he termed "dialogic," characters' voices are differentiated through phrasing, syntax, and differentiated voice. In Dostoevsky's novels, characters tend to have unique voices, and in addition to talking to others, they talk to themselves, engage themselves in dialogue about choices and actions. In dialogic novels, characters have more fully formed personalities interacting with others as if they were in the "real world." Dialogic novels tend to be messy. They eschew perfect solutions as characters' fates are worked out according to their own internal logics as reflected in their choices, behaviors, and voices. ${ }^{6}$

Bakhtin observed a phenomenon of the dialogic novel he called "carnivalization." In response to power and the tendency for one voice to dominate the narrative, other characters would look for opportunities to upend the power structure, to transgress boundaries by violating social mores or customs. In this way, "carnival" functions in novels the way it does in spring celebrations that allow costumes and theatre to upend social hierarchy and provide the kind of humor normally not permitted. Carnival in novels allows characters to parody the power in the world they live in or use humor or playfulness as a way to inject their own voices into the narrative. In Bakhtin's analysis, voice is subject to power, but it finds ways to burst into the open through openings created by "carnival." Educational theorists have imported Bakhtin's observations about the social world and voice into the classroom, noting that some classrooms are monologic while others are dialogic. ${ }^{8}$ In monologic classrooms, the teacher's voice dominates the discussions and is the only voice authorized to speak. Students, if they wish to speak, need to learn to speak like a teacher, in the teacher's voice. This observation echoes Bartholomae's observation that students need to "invent the university" in their own voices by mimicking the voices they hear around them in the academy. They do so by constantly negotiating their way into the community, sometimes through carnivalizing.

Paulo Freire speaks of "narrative sickness" as an aspect of this same educational problem of monologism, of the teacher's voice dominating the classroom. ${ }^{9}$ In Freire's analysis, the teacher narrates reality to the students with rules such as these in play:

- the teacher teaches and the students are taught

- the teacher knows everything and the students know nothing

- the teacher thinks and the students are thought about

- the teacher talks and the students listen-meekly. ${ }^{10}$ 


\section{FEATURE}

Bakhtin, Freire, and Vygotsky all equate the freedom to speak in one's own voice with a form of liberation, the right to be one's own self and to speak in one's own voice. Oppression of voice is a major part of oppression of the self, the exercise of power to stifle other voices and selves.

In these theorists, we find a subtle but powerful convergence between the concept of voice and the concept of space. Space can be imagined to allow for authentic voices to speak, or it can be structured with rules that cut off the possibilities for such speaking, rules that prohibit speaking at all, or rules that prescribe specific authorized ways of speaking. By insisting that students develop academic voices to write certain kinds of academic papers, we create a kind of monologic space where only authorized ways of speaking are allowed. If academic spaces tend to be monologic and rulebound, then theories of "Third Space" can help us understand how to function pedagogically in such spaces. Third Space, derived from Henri Lefebvre's work, The Production of Space, is based on the view that culture is achieved through a shared understanding of rules and structures. ${ }^{11}$ We function in a culture by knowing what we can and should do in given space. However, we also have the choice to transgress boundaries and misbehave, whether to make a statement (in cases of civil disobedience, for example) or because we fail to understand the rules or structures in the first place. When such transgressions occur, everyone involved has the opportunity to generate a Third Space. Third Space is created when humans in shared space encounter cultural difference that disturbs the stability created by rules and structures. In destabilizing space, Third Space makes room for art, creativity, humor, and playfulness. Third Space shares many traits with Bakhtin's carnival. Most importantly, it humanizes space by allowing creativity, improvisation, and humor. It narrows power differentials and creates democratic and authentic moments of mutual recognition and shared human reality. In academic environments, Third Space is a powerful pedagogical space. Indeed, one primary way that teachers maintain power is through "monologism that attempts to stifle dialogue. ... The only space where a true interaction

between teacher and student can occur . . . is in the middle ground, or 'third space."'12

In what follows, we will describe two experiments with academic voice. These case studies involve librarians as significant shapers of a Third Space experience. Librarians might reasonably be ambivalent about such experiments. On the one hand, libraries historically have been shaped by rules and structures that can easily be connected with monologic, academic thought. Librarians have traditionally produced a space of silent contemplation with voice often considered disruptive. Most libraries today still have silent spaces where anything above a whisper can cause raised eyebrows. Yet most librarians also tend to understand the tensions in that role, and we live in a space of negotiation between the rules that impose silence and order and the space that generates excitement and ideas. Most libraries today have ongoing experiments with different kinds of spaces, including experiments that violate more traditional library norms. As advocates for student learning, we can shape the library as a space receptive to authentic student voices and their efforts to "invent the university" through playfulness, parody, and sometimes resistance. The two case studies that follow suggest ways to develop such practice.

\section{KELLY: THE SECRETS WALL AT THE UNIVERSITY OF IOWA}

Students often come to university underprepared not only academically, but "with attitudes, norms, values, and behaviors that are often at odds with academic commitment."13 The University of Iowa administers the MAP-Works survey to all first-year students, making it possible to identify, for example, anyone who plans to spend fewer than five hours a week studying, yet still expects to get straight As. Individual outreach to students offers targeted support and possibly helps manage their expectations. Offices ranging from Academic Advising to Student Health and Wellness provide workshops, educational materials, and other outreach to guide students into recognized successful academic habits. Though this work is tied to institutional goals of retention, it also reflects understanding of the gap between common characteristics of students as they enter university and those of successful students. Students coming directly from high school might rejoice at the reduction in seat-time for their university courses, but find themselves unequipped for the self-directed pace. Strategies such as regularly reviewing class notes, dropping in on professor office hours, and organizing a study group may be completely foreign to new students.

The gap between typical and ideal behavior becomes highly visible at the end of the semester. University-level final exams and term papers can be a rude awakening for students. The attitudes, norms, values, and behaviors they have been practicing all semester can come to pointed conflict with the rules and expectations of their professors and the university. The last time I worked the reference desk during the week before finals, a student asked me for help finding his course textbook for the first time. However, he couldn't remember the course title or his professor's name, let alone the title of the book. Though this may seem like a worst-case scenario, we might imagine that for each student who comes to the reference desk, there are others in the same situation who do not ask for help. Even students who have been doing their coursework all term may struggle with test anxiety, time management, and other barriers. The artificial and highly rule-bound practice of final exams rarely lends itself to student creativity or flexibility. The physical environment during a final exam can be restrictive and intimidating: in a huge lecture hall, students write the timed exam in complete silence, and may be limited to a single bluebook or multiple-choice Scantron form. Even the scheduling of final exams can be perplexing to new students, as they generally 
occur at a time and in a location where the class has never met. The final exam may represent a significant percentage of a student's grade, pit her against her classmates through a grading curve, and potentially determine her ability to continue in her chosen major and field, or to receive some types of financial assistance.

Many academic libraries offer special services and programs during the end of the term, including craft breaks, board games, sessions with therapy dogs, designated napping spaces, and of course, free snacks. ${ }^{14}$ These programs have names such as Stressbusters (University of California, Los Angeles), De-Stress Island (Biola University), Stress Free Finals Week (University of Houston), and Dance Your Stress Away (University of Maryland). These names show that the problem of student stress during finals is clearly recognized by staff, and library programs often occur in conjunction with initiatives from other units. Anxiety disorders, alcohol abuse, and other mental health disorders are strikingly common among university-age people..$^{15}$

The Secrets Wall is one of several activities offered at the University of Iowa Main Library to support undergraduate students during final exams. Although originally launched as a means of stress relief, the Secrets Wall also offers an alternative form of casual peer education, with opportunities for reflection and conversation. However, unlike a formal peer education program, which transmits official messages refracted through the voices of student mentors, the informal sharing of information through the Secrets Wall can be controversial, irreverent, offensive, and undeniably authentic. The Secrets Wall creates what James Elmborg has called "an indeterminate and open space with the potential for adventures and surprises" for participants and observers alike. ${ }^{16}$ As a Third Space, it offers students an outlet for authentic self-expression and dialogic information sharing between peers during the constraining, confusing, and stressful period of final exams.

The University of Iowa Main Library was constructed in 1951 and saw its last major addition in 1972. In Spring 2012 work began on a major renovation of the first floor to create the undergraduate-focused Learning Commons, a "tech-infused comfortable and flexible learning space and one-stop academic and information help center . . . with good coffee!"17 The Secrets Wall was first implemented during the construction period. This project was inspired by the website PostSecret, which consists of scanned images of anonymous postcards sent from all around the world. Each postcard shares a brief secret, ranging from the banal to the tragic. Since the project began in 2004, at least 500,000 secrets have been posted, and the site claims to be "the largest advertisement-free Blog in the world," with over 678,600,000 visitors as of this writing. ${ }^{18}$ Selected images have been published in six separate books. PostSecret suggests that releasing a burdensome secret into the world can be healthy, perhaps even a form of self-care or healing. ${ }^{19}$

PostSecret's success certainly demonstrates that anonymous secrets have broad audience appeal. Anna
Poletti proposes that the materiality of the scanned postcards strengthens their authenticity. ${ }^{20}$ There is no identifying trace of the individual confessors, while the unique handwriting and aesthetic qualities show individual efforts. Although social media sites offer numerous virtual spaces to share secrets, the threat of exposure through account information or IP addresses looms over any desire for anonymity. In this context, a handwritten note provides a counterintuitive opportunity for anonymity, even if it is scanned and posted online by a third party.

Inspired by the openness of PostSecret, the Secrets Wall simply encourages participants to "post a secret," with no other instructions. For each of the three semesters this project has run, the Secrets Wall has been available from the Friday before exams through the end of finals, a period when the building is kept open 24/7. The first year, blank Post-It notes were attached to one of the brightly painted construction walls. Since the completion of the Learning Commons, small colored squares of paper have been taped up to a moveable whiteboard. The contained writing surface maintains the intimacy, forcing passersby to come close to read. Each year, additional paper has been taped up onto the wall by participants, sometimes $81 \frac{1}{2}$ by 11 sheets, printed photos, or small scraps. Each year, some squares have been removed, whether by the original writer or someone else. A staff member removes any notes listing a phone number, and staff would remove any hateful speech, though that has not come up.

And what do the secrets say? Let's examine some of the approximately 250 secrets left at the end of finals in Spring $2014 .^{21}$ Much of what gets confessed appears at first terribly silly. There are admissions of embarrassing favorite movies and multiple confessions of not wearing a bra or having just farted. There are rants about hard classes and commiseration about tough TAs. Some posts wish everyone good luck during finals, though one person writes that they hope others do badly, to boost the curve. Many comments address issues of schoolwork: seventeen notes used the word "finals" and many others refer to studying. Unsurprisingly, a good portion of the notes refer to sex, love, and other relationships (thirty-six specifically about sex or STDs, twenty-five about crushes, marriage, and dating). Relatively few notes mentioned drugs, although several of those referred to drug use in academic pursuits (e.g., "I study on coke" and "drunk in the lib, don't care"). Two notes mention suicide attempts. In previous years, notes referred to problem drinking, so this year I provided brochures from University Counseling Services and Student Health and Wellness.

Unlike the PostSecret website, the Secrets Wall offers the opportunity for back-and-forth conversation. Notes are posted in easy reach with an abundance of pencils, inviting viewers to reply. Instead of a deposit of standalone secrets, what emerges is a messy, dialogic conversation. Forty-three individual notes clearly had more than one author, and sixteen notes explicitly respond to other notes. (These included anything with an arrow pointing at another note, notes with 


\section{FEATURE}

two or more wildly different handwritings, and small conversations happening within one piece of paper.) At the very least, this demonstrates that people are reading the secrets, but it also suggests an interest in engaging. The result is an asynchronous, anonymous, temporary community. One of these conversational notes reads, "My friend is cheating." Another comment, linked with an arrow, encourages the writer to "tell professor." Another note had, presumably, three unique authors. The first comment reads, "I hate freshman. Their ignorance is not bliss." Someone has drawn an arrow to this, asking, "were you not one once?" A third addition states, "well done sir." The call to empathy in this interaction demonstrates an understanding that university is a time of growth and learning. Some students themselves recognize that their peers may lack the knowledge or skills they need when they first get to university. Although we don't know what specifically the original writer hates about first-year students, the distaste for their ignorance suggests the person is an older, wiser student.

As George Kuh et al. have written, "The role of peers in creating vibrant learning environments cannot be overestimated."22 The informal information sharing of the Secrets Wall hardly has the heft of collaborative classroom activities or peer mentorship programs, but the messages can be powerful. One student writes about the hard realities of academic success: "Finally figured out my major. But I need (a) least 3.5 for graduate school, going into my 3rd yr w/ only a 2.5 . . ugh! Fuck me :/." The problems this student describes-choosing a major relatively late, then realizing that they may not be able to get their grades up to get into a graduate program-are far from unique. A variety of attitudes, values, norms, and behaviors might lead to this unhappy position, and this student has shared their regret. There is no way of knowing how many other students read this post, let alone internalized its message, but this testimony demonstrates this student's reflection and learning in their own authentic voice.

Though the Secrets Wall is aimed at our undergraduate population, anyone passing by might contribute, and certainly many people do stop and read. Very few comments about the project have made their way to me, although I did receive some concerns during one semester when the board was placed at the entrance to the library's collections, directly visible by anyone entering the library. When placed to the side, still visible but with the secrets not legible until you choose to come closer, no negative feedback has been reported. This past year, as a colleague and I were putting up the blank papers, we had several interactions with passersby. One person asked what it was for, and after I'd explained, he wrote something as we were still working. Another wrote without saying anything to us at all. Finally, two other students commented to one another that, "the comments on there are always really funny." By the time I left the library that afternoon, at least a dozen of the blank papers had been written upon.

What, ultimately, is the value of the Secrets Wall? Unlike other participatory initiatives (for example, the University of Iowa's \#captureiowa project, which encourages first-year students to tag photos of their campus experiences), there is no underlying goal of assessment. There are no identified learning objectives. Yet, gauging by how quickly the board fills up, the Secrets Wall clearly meets a need. Students find it compelling enough to share in, to read, and to comment. Among the mildly lewd jokes and rants, there are gems of raw student experiences. Elmborg has written that "fewer explicit structures imply openness to improvisation and invite community, a willingness to be appropriated by library users for their own ends."23 The Secrets Wall exemplifies that openness and invitation to community as a low-stakes, low-barrier opportunity to engage with others. By providing a place to share experiences, students may find themselves connecting with the diversity of campus in ways they may not encounter face-to-face. The Secrets Wall also demonstrates some of the Iowa Libraries' institutional values, the layers of "how we do things here and what things really mean" that make up campus culture. ${ }^{24}$ For undergraduates who think of libraries as silent, shushing places, and who have not explored the depth of controversial materials in our collections, the Secrets Wall introduces the idea of intellectual freedom. Students see that their voices have a place within the library, and that the library respects and promotes free speech and expression. By weaving this self-expression and sharing into the fabric of finals, the Secrets Wall provides an additional way for students to understand their experiences, whether overwhelming, infuriating, or absurd.

\section{HEIDI AND ROB: WIKIPEDIA AND HISTORY ON THE WEB}

Do all history classes start with the professors saying "we really don't know much about the subject of this course. But let's all figure it out as we go along."?

-A second-hand report of non-major's comment after the first day of "History on the Web," January 2014.

For God's sake, you're in university; don't cite the encyclopedia.

-Jimmy Wales on Wikipedia ${ }^{25}$

The title of Chandler and Gregory's 2010 article "Sleeping with the Enemy: Wikipedia and the University Classroom," summarizes much of the attitude toward Wikipedia on many university campuses. ${ }^{26}$ More often than not, Wikipedia is treated as a "necessary evil" or an aspect of the contemporary information world that faculty and librarians don't need to like but must accept lest we be construed by our students as uncool, out-of-touch Luddites. When we-a historian and a librarian-talk about our work with Wikipedia in the classroom with colleagues, there's often an underlying sense of unease: part "you should know better" and part "you're sleeping with the enemy." There is often a lingering unarticulated hope that we're using Wikipedia to teach students that "our" way is 
better-that while we may have dalliances with Wikipedia, our true allegiances are with "proper" scholarly resources.

Ignoring Wikipedia in the classroom or emphasizing only its faults limits the kind of conversations we can have about this ubiquitous resource. Wikipedia, as Jacobs argues, is a rich space for problem-posing information literacy work as it "allows us to consider how knowledge is created, produced, and disseminated, and to interrogate our current understanding of scholarship, scholarly authority, and the academy." ${ }^{27}$ In team-teaching History on the Web to thirdand fourth-year students at the University of Windsor in the spring of 2014, we wanted to provide students with an opportunity to think critically and creatively about historical knowledge in the digital age. Having class in the Information Literacy room in the library, rather than a traditional history classroom, suggested to students that this was not going to be your typical history class.

Rather than focusing students' attentions on consuming or reading history, we instead concentrated on how history is created, produced, and disseminated in the digital age and how they could participate in this realm. Further, we wanted our students to engage in the vital and evolving questions about public and academic history in the digital age. What are the implications of the digital age on the writing, teaching, creating, and consuming of historical information? Who writes it? Who contributes to it? Whose points of view are represented? Whose points of view aren't represented? Who makes information accessible or inaccessible? Who makes decisions about accessibility or inaccessibility? The only real way for students to fully explore these questions, we believed, was to put them in the role of maker of historical information.

The semester-long Wikipedia assignment we developed for this class became a rich space for students to engage in problem-posing questions about historical information and to engage with large, pressing issues related to academia's roles within in the twenty-first-century information universe. Neither of us had any preconceived ideas about what would happen with these assignments but what happened far exceeded our hopes and expectations.

In the first week of the semester, groups of students were asked to select Wikipedia entries on historical topics. Over the course of the semester, students would improve the essays by writing at least one thousand words of new content, adding footnotes and sources, reorganizing content and otherwise improving the quality of the entries. We encouraged them to find ways to generate traffic to their site by creating links both to and within related entries and by creating controversies to get conversations happening within the talk and edit pages. Humor and playfulness were often used in these controversies-as it is in the carnival—as a way of revealing hidden truths within power structures. Creating controversies was a way for students to disrupt Wikipedia and to test its boundaries, challenge its practices, reveal its assumptions, and unmask its power structures.

Throughout the semester, we provided numerous opportunities for groups to discuss and share how their entries were coming along and what issues they were confronting. In this way, the class learned from each other and we used these discussions as a way to ask them to interrogate and explore Wikipedia further. We wanted them to immerse themselves deeply into the Wiki-trenches and engage with both Wikipedia and Wikipedians, pushing and prodding both to test limits. As part of their final assignments, we asked students to summarize what they learned and reflect on the process and experience in a three-to-five-page reflection letter. Our students' conversations, comments, and reflection letters revealed that Wikipedia raises many questions, poses many problems, and offers numerous ways to consider how historical information exists in the digital age both in terms of academic history and public history. ${ }^{28}$

As the semester progressed, Wikipedia became a sort of Third Space in the ways that Elmborg describes: "a place of transformation where we can transcend polarity and give rise to new selves. Represented space is rigid, controlled, policed, and defined. Third Space is (at least potentially) open, symbolic, playful, and generative. It can also be contested space if power differentials force confrontations between conceptual systems." ${ }^{29}$ As Elmborg further argues, Third Space

provides a concept, whereby people with less obvious social, political, or military power can still exert influence on space by revisiting the represented structures of dominant cultures. They do so by simply occupying space and appropriating it for their own purposes. They carry with them social and cultural borderlands that create the need for negotiating and the refashioning of meaning. ${ }^{30}$

For our students, interacting with the Wikipedia borderlands in sustained ways raised all sorts of questions for them regarding power, authority, openness, structure, and negotiation of all these entities: many began to look at academia and at themselves as historians through transformed lenses, constructing new versions of self and voice in the process.

The element of play within this Third Space was vitally important for our students as they interacted with their topics, each other, other Wikipedians, and Wikipedia itself. For many students, Wikipedia became an increasingly communal space. We encouraged students to test Wikipedia's boundaries to explore Wikipedia's limits, limitations and possibilities. At times, the students' work with Wikipedia took on a playfulness that resembled Bakhtin's discussions of the carnival as they challenged and disrupted norms of academia and scholarship. As Bakhtin writes, "One might say the carnival celebrated temporary liberation from the prevailing truth and from the established order, it marked the suspension of all hierarchical rank, privileges, norms, and prohibitions." ${ }^{31}$ The carnival challenged

all that was ready-made and completed, to all pretense at immutability, sought a dynamic expression, 


\section{FEATURE}

it demanded ever changing, playful, undefined forms. ... We find here a characteristic logic, the peculiar logic of the "inside out," of the "turnabout," of a continual shifting from top to bottom, front to rear, of numerous parodies and travesties, humiliations, profanations, comic crownings and uncrownings. ${ }^{32}$

Through Wikipedia, several groups played with authority and toyed with academia's bedrock by publishing, albeit temporarily, blatantly false information, some in trickster-ish ways and others in defiant ways. While some might see the playfulness of our students as "anti-academic" or "contrary to librarian ethics," we believed it was imperative that students explore this terrain and make discoveries for themselves rather than follow accepted academic norms unquestioningly. As danah boyd has argued about teens, "They need to know how to grapple with the plethora of information that is easily accessible and rarely vetted. And given the uneven digital literacy skills of youth, we cannot abandon them to learn these lessons on their own." 33 Playfulness, in other words, was the means through which we believed our undergraduate students could learn those lessons and get beneath the façade of Wikipedia to see, understand, and evaluate its foundational assumptions and practices in relation to those of academia more fully.

Having been well trained in the importance of providing accurate, reliable, and documented information throughout their history degrees, a few groups relished the opportunity to turn the academic world on its head, if only temporarily. The group working on the Machu Picchu entry, for example, went on to test the boundaries of Wikipedia and academia unabashedly. First, they made claims like this:

Scientologists believe that their founder L. Ron Hubbard was the re-incarnation of the Incan king Pachacuti, who was believed to be a direct descendant of an alien from the highest class of elites. Pachacuti's (2005, 195) travelled to earth from a distant planet after being banished by Xenu. These thetans were re-incarnated into Hubbard upon Hiram Bingham's meddling at Machu Picchu in 1911. It is no coincidence that Hubbard was born in March of that year which was the precise time that Bingham had re-discovered the lost city. ${ }^{34}$

Not surprisingly, responses to this addition were fairly quick. As might be expected, the first editor removed the above paragraph. Interestingly, the first edit was made not for factual inaccuracies nor for suspected vandalism but rather for its lack of citation. Intrigued by this edit, the two students, Rob and Adamo, wanted to see if a false citation could restore the paragraph. They added this fictitious but convincing looking citation: Garrison, Hubert (2013). "Scientology and Hubbard's Origins." Scientology Americana 2 (1): 4-6. After the fake citation was added, the paragraph was allowed to remain. The message the students took from this is that as long as information is cited-albeit with a convincing looking but fake citation- it was acceptable on Wikipedia. Eleven hours later, the above paragraph was removed but not because of the fake citation or factual inaccuracy: none of the responding Wikipedians appear to have fact checked this group's claims or the citation. Instead, the editors focused on the placement and relevance of the information. As one editor wrote, "I've removed the paragraph about L Ron Hubbard as that bit of info may fit in his biography or the religion article, but is rather irrelevant here." ${ }^{35}$ The closest they got to having an editor call them on their outrageous claims was the editor who said he "remove[d] some silliness about aliens ... probably more should go." ${ }^{36}$ The added paragraph was finally removed almost twelve hours later by the editor who found the additions related to Hubbard irrelevant or out of place. No one ever pointed out the citation was fictitious. This group knew that, like Bakhtin's carnival, their transgressions of scholarly protocol were temporary: order would eventually be restored by more diligent editors.

This carnivalesque episode revealed to our students that - in some cases - the mere appearance of scholarly authority and accuracy was sufficient to placate some editors: accurate information could be deleted if it did not have a citation and inaccurate information could be restored if it had a citation of any kind. As professors of the course, we were not safe from our students' carnivalesque tricks. In their reflection letter they wrote: "of all the changes made on the Machu Picchu page, the most insightful and informative is that the correct pronunciation and spelling is in fact Machu Pikachu." ${ }^{37}$ This sentence made us laugh but also gave us pause: was it a joke? We looked it up to make sure it was a joke and in so doing we were reminded that everyone needs to ask critical questions about information. In this way, the carnivalization of Wikipedia can offer an incredibly valuable opportunity for information literacy instruction for both teachers and students.

Our students' other history professors and their librarian have all talked with them at length and in different contexts about needing to be critical information users. For many students in this class, however, those words of caution only came to life with this group's playful experiment. Not surprisingly, they had to experience it and teach themselves this lesson for our words of caution to truly resonate with them. The Machu Picchu group's "silliness" revealed some very interesting things to the class about Wikipedia and Wikipedians. The lack of fact checking, or not citing fact checking as a reason for deletion of content, disturbed many in the class as did the fact that a false citation could stand as "evidence" for a blatantly false claim. This group's experiment suggested that, with this particular entry at least, outrageously incorrect information could be seen as more or less acceptable if it was documented (even with a false citation), placed in a relevant section, and not be "silly." In inverting the scholarly world, if only temporarily, this incident revealed important things to our students about Wikipedia, in particular what is valued and not valued in the Wikiverse. By extension, it also reveals and makes visible what we value in scholarly writing 
and academia: reliability, expertise, authority, accuracy, and documentation.

Similarly, some of the other playfulness we saw during this project was attempting to be overtly subversive by challenging a daunting Wikipedia reality: the predominant white, male, American bias of Wikipedia. Although we read and talked about articles pertaining to gender and race biases within Wikipedia, it wasn't until one group started interrogating the state of the articles about Canadian women's contributions to the World Wars that they saw how insidious the male bias can be within Wikipedia. ${ }^{38}$ In selecting their entry, the Canadian women's group noted the pitiful state of the entry on Canadian women's contributions to the war efforts: it needed substantial work in terms of content, citations, and organization. This group hoped that by improving the essay they could bring more traffic to their page and thus more attention to the forgotten history of Canadian women in Wikipedia and, it was further hoped, in the culture at large. When they didn't see much increase in traffic, they playfully deleted the entire first paragraph of the entry on Military History of Canada During WWI and pointedly replaced it with this: "Canadian women played a quintessential role in the First World War. Without their contributions, the war would not have been won for the allied powers. The world owes Canadian women a debt." They added a link to their page hoping it would generate controversy and bring more traffic to their improved essay. Within three hours, their paragraph was dismissed as vandalism, summarily deleted, and the original paragraph restored. No controversy was sparked and the page received no additional traffic.

Our students, however disappointed, learned important lessons. This group experienced first-hand what they had heard in class and understood theoretically: within history, especially public history, some voices and stories are privileged over others. Although disheartened that their brief engagement with the carnivalesque did not bring much attention to Canadian women's contributions to the war effort, this group felt like they were using their voices and their background in history to make a small but significant difference in the historical record on Wikipedia. As they wrote, "this project gave us the opportunity to contribute to a neglected history page expanding and adding to history on the web." ${ }^{39}$ It was a small step but an important step. Again, learning these lessons first-hand, for themselves, helped to concretize the abstract issues we often talk about in classes about bias, voice, and privilege.

Like the carnival, Wikipedia explodes our usual notions of power and authority. In the academic world (not to mention many other aspects of society), university-educated people possess a particular kind of privilege and ethos that often goes unchallenged. In Wikipedia, however, one's credibility is not at all dependent upon years spent in higher education or degrees granted. It is based instead on the number of edits logged and experience garnered in the Wikipedia universe. It was jarring for our upper-level, high-achieving students to have their edits overridden, written over, deleted, or challenged on historical topics that they felt more than well qualified to write upon. Their course work, grade point averages, skills in reading, writing, and researching mattered not one whit when confronted with Wikipedians with extensive edits to their credit. Our students came to realize that their academic skills and scholarly credentials were worth virtually nothing in the Wikiverse. Instead of being seen as experts in their field of study, our students were treated as newcomers with little to offer and much to learn.

Wikipedia acknowledges there are often tensions between new and experienced editors and they even have a page dedicated to relationships between these groups called "Please do not bite the newcomers." ${ }^{\text {" In }}$ its own bit of carnivalesque playfulness, the editors of this page also provide a link to a page called "Please bite the newbie," where, in the first paragraph, we are warned "this page is intended as humor" and then given advice like "Wikipedia always has lots of newcomers that drive you up the wall. We must be extremely hostile to them for them to understand the true meaning of Wikipedia." ${ }^{41}$ Interestingly the phrase "extremely hostile to them" links to another page warning against the practice of "Wikibullying." "2 The carnival uses humor to expose aspects of society that often go unnoticed or unnoted: the use of humor on these pages exposes some definite realities of the Wikipedia underworld. If our students had not been required to spend a semester working on one site, they may not have been able to fully engage with a range Wikipedians over time. By engaging with Wikipedians along with Wikipedia, our students saw the kinds of conversations that go into shaping and determining what gets published and whose voice gets heard and what power structures underlie those conversations.

Undoubtedly, the role of editors is to maintain quality control and oversee factual accuracy of the entries so as to ensure the authority and trustworthiness Wikipedia wants to claim. Although our students knew this editorial intervention would happen, many of them struggled with their interactions with other Wikipedians. One night, the group working on the entry about the Eastern Front in World War One noticed that an editor kept undoing one group member's edits. The students decided to take this editor on and adopted an "under siege" mentality to create a protective perimeter around the group member's edits. This group of students took the undoing of edits as an affront and in class they routinely used combat metaphors to describe the battle in which they were engaged. It was clear that they felt protective of the little amount of credibility and authority Wikipedia granted them, especially when they are used to having a certain amount of credibility and authority as upper-level history students. As they wrote, "Perhaps it is the fact that we consider ourselves 'trained historians' and we carry ourselves with an ounce of smugness on the Internet, or that the history discipline attracts a certain kind of individual; in any case, having one's work ruthlessly edited by 'ANNOYMOUS' or completely removed arbitrarily by a long-standing editor is painful." ${ }^{.43}$ However, by the end of 


\section{FEATURE}

the semester, this group understood that this long-standing editor's revisions weren't meant as personal attacks on them or challenges to their intelligence. Rather, they realized, he "made our article considerably better. [He] deleted our content and edited our writing, but he did so with good intent, always justifying his edits and private messaging us with editing guidelines and formatting tips and tricks. ${ }^{.44}$ While our students did encounter well-intentioned editors like the one described above, some of our students had run-ins with well-established Wikipedians.

Most problematic were the editors who took on a sort of gatekeeper role and routinely pointed out our students' violations of various bits of Wikipedia protocol, procedures, and etiquette. One group encountered a troll-like editor who was impatient, cantankerous, and often rude to these clearly fledgling Wikipedians. In contrast with this type of Wikipedian, the Eastern Front editor came to model what a good editor might look like. In this way, our students began to see the potential for Wikipedia to be a community or a forum for nurturing, encouraging, and perhaps even mentoring young contributors and scholars in positive ways. They wrote, "After completing this project, we saw Wikipedia as not only a place to quickly obtain reference information, but as a tool for scholarship. Wikipedia creates space for an interactive dialogue on a multitude of subjects. ${ }^{\prime 25}$ Wikipedia pushed our class to see that strong scholarly conversations are not monologic but dialogic.

By asking our students to disrupt Wikipedia, to engage in it as a Third Space, and to invoke the carnivalesque, they began to disrupt dominant ideas about Wikipedia, the production of knowledge, and academia. These students not only have a better sense of how Wikipedia works as an entity but also how academia works in terms of voice, power, and authority. Through their activities in the Third Space that is Wikipedia_carnivalesque and otherwise-our students saw that while Wikipedia calls itself "the free encyclopedia that anyone can edit" there are definite limitations to the terms "free" and "anyone." ${ }^{\text {"6 }}$ Just like academia, Wikipedia has its procedures, its values, its sources of power and authority, and its hierarchies, its biases and its limitations.

Writing for Wikipedia, a resource that has been all but banned in most of their courses and education, was an inversion of standard academic protocol for many students. Above all, students were able to participate in a shareable and collaborative writing of history which is an endeavor undergraduate students (not to mention members of the public) have been long barred from doing in the closed, elite, highly credential-based world of scholarly writing and publishing. Students came to see Wikipedia as a possible forum for knowledge creation and dissemination and an endeavor students could actively participate in and contribute to, not merely consume. In this way, our students transcended multiple borders and claimed a particular kind of power in so doing. Some students saw their efforts to improve articles as helping younger versions of themselves. As one group wrote, "just as we take pride in our papers and assignments, we take considerable pride in our Wikipedia entries. The thought of our work possibly being utilized by some high school students for their research paper on the First World War was very exciting, but also daunting ... we took great pleasure on acting as custodians of Wikipedia." ${ }^{\prime 47}$ Others saw their efforts as a way to redress wrongs or omissions in Wikipedia and perhaps even public history.

The group working on the Second World War Japanese internment camps in Canada entry wrote, "The entirety of Japanese Canadian history and social tensions between the Japanese and Canadians was summed up in just 300 words. Still, there is hope, so long as students like us are around, there is a chance for improvement. Wikipedia may not be the greatest source available but we can strive to make it as good as we possibly can." ${ }^{148}$ While few students phrased it as such, most of them wrote in their reflection letters or mentioned in class that their voices found a mode of expression not often granted to them as undergraduates. One of the students working on the Japanese internment camps entry wrote, "it is cool to think that in [the] future, people looking to learn more about this important piece of Canadian history will be reading work that we have done. It may be a while before I have anything officially published in an academic journal, but anyone who goes to the Japanese Canadian Internment page will end up seeing my work, which is cool to me. ${ }^{.49}$ For most of our students, this assignment was the first time they had been able to use the skills they have learned in their classes in a public forum or in ways they perceived could make a difference in the world.

While we had originally thought our students would enjoy this project, we could not have envisioned how empowering and transformative it would be for some of our students to do work of this nature. When we first designed this assignment, we hoped students would come to see Wikipedia not as something inert but something living, active, breathing, created, evolving and, most importantly, changeable. More specifically, we wanted students to see Wikipedia as something they could use their voices and expertise to change and make better. Students rose to this challenge admirably and all but a very few took on a level of responsibility, ownership, and pride that we have rarely seen in other academic assignments. Our students taught us many things we could not have discovered on our own. Perhaps the most powerful part of this assignment for us was to see that most of our students realized they were not just writing for their professors: they were working toward something larger than a final grade, something that could potentially make a difference in the ways people saw or understood history. Seeing our students empowered in this way confirmed our commitment to this kind of information literacy/ history assignment.

As one might predict, our students pointed out many flaws of Wikipedia. However, what was interesting and inspiring to us was how many positive aspects students saw about Wikipedia. Indeed, it was riddled with bad writing, incorrect citations, neglected topics, problematic statements, troubling biases, and draconian editors. But Wikipedia 
offered a forum where our students could add their voices to the dialogic narrative of history and participate in making Wikipedia better for other students and members of the public. As we reviewed our students' reflection letters at the end of the semester, we were particularly interested in the ways in which students talked about their voices - changing the academic voices that they had carefully crafted and painstakingly honed over the years of their degrees into something more accessible and public. Students articulated an evolving understanding that the voices they needed to use in Wikipedia were somehow different from their academic voices. Our students had to begin trying on "new" voices and many were excited to see that the writing of history could take place in a range of forums and modes outside and inside of the classroom. As one group remarked: "Wikipedia teaches history students and academics to write more clearly for a public audience, a skill that has a positive impact on academic culture, and one that can be transferred into many different work environments." ${ }^{50}$ Here, this group explores the idea that the scholarly voice of history, the one that has been foregrounded throughout their schooling, is but one of a myriad of different voices they could use to convey their understanding of history and to participate in the world.

This assignment and students' responses to it confirmed hunches that we both had that many students need or want opportunities to use their voices and scholarly knowledge in a range of ways. Some used their voices to disrupt Wikipedia, some to make it better, some to try to make a positive difference in the world. All of the students' responses to this project underscored for both of us the need to develop more assignments and activities where students can see that the story of history is not monologic but dialogic and that their voices are important and necessary parts of that dialogue.

\section{JIM: COMMENTS AND CONCLUSIONS}

In conclusion, we want to emphasize the ways that these innovations in library practice are explicitly connected to the educational theories of voice as they were articulated in the introduction. In the process, we want to illustrate the ways that carefully applied critical theory can guide pedagogical practice in future Third Space work in the library. Without such critical context, the Secrets Wall and History on the Web might seem idiosyncratic or even random in their efforts to engage students in some vague form of fun or creative classroom activity. Our goal has been to demonstrate that underlying these initiatives are sophisticated pedagogical theories that can help us understand these instructional practices in important ways. In these concluding remarks, we want to explore those goals and reconnect them explicitly to the critical theories they illustrate.

As Bartholomae tells us, we are all of us "inventing the university" as we go about the intense verbal negotiations we use to demonstrate that we belong in the academy. ${ }^{51}$ We all do this at every level, from incoming freshmen to full professors.
Academic discourse is not natural, far from it. Students need to be initiated into the world of academic conversation, and they need to continue to be taught until they ultimately become fluent in this environment. Both the Secrets Wall and History on the Web decenter the librarian, the professor, and the library as sources of authority, thereby creating a space for social discourse as a learning space (as opposed to a teaching space). In this decentered model, the traditional experts give up their positions as gatekeepers and standards-enforcers, assuming instead positions as guides in unmapped spaces. In History on the Web, the professor and librarian begin the course by confessing they do not know what will be learned. On the Secrets Wall, no one can arbitrate what an appropriate or inappropriate secret might be. However, the end result is not "anything goes," but rather, everything is "up for negotiation," with "voice" the tool for negotiating. When students post things the community finds inappropriate (either in Wikipedia or on the Wall), the community itself negotiates the standards openly and directly. Students have the opportunity to "put something out there" and to check back later to see how the community "referees" its presence. Impersonality is key to the Secrets Wall and to History on the Web. Students have a safe space to try out various voices to test what works in the communities they hope to join. They receive immediate feedback from the community about their voices, but this feedback comes through disembodied channels and not as personal critique. Perhaps most importantly, each of these two projects takes place in what Lefebvre calls "dominated space." ${ }^{52}$ The classroom and library are two extremely rulebound places. Appropriate practices are explicitly prescribed and reinforced. When these dominated spaces are thrown open to improvisation, students are invited to carnivalize, to invent their own rules, to try out identities and strategies, to "invent the university" in ways that make sense to them at their point in time and development.

Academic work is serious business with high stakes consequences, but we need always to remember that having fun is part of what motivates students and helps them cope with pressure. It is also crucial to learning. As students learn to negotiate entry into academia, humor helps them deal with many basic challenges. The first challenge is the nagging fear that they may not belong or that they may not have what it takes to succeed in the university. This fear exists at all levels of entry into elite organizations and has been labeled the "imposter phenomenon." ${ }^{153}$ As undergraduates, and especially as freshmen, students are at the very bottom of the power structure in academia. They regularly use humor to alleviate and explore their feelings about this positioning. Bakhtin identifies "carnivalization" as an intentional way that those without power can begin to negotiate their relationships with those more powerful. Students use humor to make fun of themselves, and to make fun of their surroundings with the goal of lessening the pressure to perform and ultimately to succeed.

Humor has a powerful social function. It punctures pretensions and closes distances. Humor allows students to make fun of their own mistakes and to (at least temporarily) bring 


\section{FEATURE}

the power under their own control. As Mary Louise Pratt has persuasively argued in "Arts of the Contact Zone," students develop a series of strategies that help them negotiate with the contact zone of the university. These include "critique, collaboration, bilingualism, mediation, parody, denunciation, imaginary dialogue, [and] vernacular expression. ${ }^{54}$ In this list we can see how students might play with language to find their own voices in the academy, often through the use of humor. Humor performs a vital function in parodying the power structure and vernacularizing the excessively formal. We see that both the Secrets Wall and History on the Web make space for all these critical functions by providing a safe place for the Third Space functions of appropriation, improvisation, and humor, all of which have the effect of taking ownership of a previously regulated space, if only temporarily.

Finally, we want to emphasize that space matters, perhaps even more now than in the past. As human spaces become more mobile and more diverse, there seems to have been an uptick in the use of space as a metaphor for all kinds of human activity. While such a claim is difficult to quantify or prove, we now regularly talk about entering a space as a metaphor for entering into new relationships, taking on a new responsibility, or changing other circumstances of our lives. Phrases like "in that space" are regularly deployed to talk about an entire kind of reality, to signal that different spaces have different rules and affordances. Holland et al. use the phrase "figured world" to capture the totality of what lies behind thinking of space in this way. "Figured worlds," they claim,

could also be called figurative, narrativized, or dramatized worlds.... The production and reproduction of figured worlds involves both abstraction of significant regularities from everyday life into expectations about how particular types of events unfold and interpretation of the everyday according to these distillations of past experiences. A figured world is formed and re-formed in relation to the everyday activities and events that ordain happenings within it. It is certainly not divorced from these happenings, but neither is it identical to the particulars of any one event. It is an abstraction, an extraction carried out under guidance. ${ }^{55}$

Figured worlds exist with their own logics, their own rules, rules outsiders do not understand. To create a coherent narrative, a narrative of the self, one needs to understand the various rules that govern behavior and speech. As a way of thinking abstractly about space, the concept of figured worlds helps us see why "space" is such a generative concept. We are increasingly aware of the proliferation of different worlds around us that we don't understand. To think of reality as one simple space we all share is, to put it bluntly, provincial.

In the case of the university, the academic figured world is "formed and re-formed in relation to the everyday activities and events that ... happen within it." ${ }^{156}$ The same is true of the library. The narratives that are available to us are played out in these figured worlds, as are the selves. Holland et al. note that "the meaning that we make of ourselves is, in Bakhtin's terms, 'authoring the self,' and the site at which this authoring occurs is a space defined by the undifferentiated 'vocal' perspectives on the social world. ${ }^{\prime 7}$ In an academic environment, any number of voices taken together constitute a discursive space, and students learn to "author the self" by creating a voice that can speak among other voices in this space. The space provides us the potential for narrative. The self, in authoring itself, must comprehend the potential narrative, individualizing it. Voice is the key to that individualization. As we look at the Secrets Wall and the History on the Web project, we can easily see the ways this creating of an "other" and unexpected space simultaneously creates the potential for new narratives. Students have the opportunity to try out drafts of their authoring voices in direct negotiation with other voices, the "undifferentiated 'vocal' perspectives on the social world." In other words, both the Secrets Wall and the History on the Web projects intentionally create a special instance of "academic space" designed specifically so students can enter dialogue with it, negotiate with it, interrogate it, and eventually come to be part of it.

Pedagogical initiatives like these provide students with important opportunities to engage academia in authentic ways on their own terms. Authenticity has long been a central challenge for academic culture. We strive to create contexts that students genuinely care about, so they can see a reason to do the work of inventing themselves as academics. Students who engage with Wikipedia in editing wars to gain attention for their causes have shifted their focus from pleasing the teacher to changing the way the world understands historical events. Students who post secrets on the Secrets Wall are (on a much more basic but no less important level) similarly learning to write themselves into academic culture. In both cases, students are putting their real academic selves up for peer review, a review that is instantaneous, genuine, and sometimes brutally honest. Without a contextual framework for understanding these pedagogical projects, they may seem merely cute or random or "one off." Our intention here has been to demonstrate that these initiatives are coherent and important in ways we can understand through critical concepts of voice and space. Such theory is available for much more experimentation and improvisation in multiple academic contexts if we recognize the importance of dialogicality, playfulness, and the generative openness of Third Space.

\section{References}

1. David Bartholomae, "Inventing the University," Journal of Basic Writing 5, no. 1 (1986): 4.

2. Michelle Holschuh Simmons, "Librarians as Disciplinary Discourse Mediators: Using Genre Theory to Move toward Critical Information Literacy," Portal: Libraries and the Academy 5, no. 3 (2005): 297-98.

3. Lev Vygotsky, Mind in Society: The Development of Higher Psychological Processes (Cambridge: Harvard University Press, 1978).

4. Vygotsky, Mind in Society.

5. Mikhail Bakhtin, Problems of Dostoevsky's Poetics, translated by 
Caryl Emerson (Minneapolis: University of Minnesota Press, 1984).

6. Bakhtin, Problems of Dostoevsky's Poetics.

7. Ibid., 107.

8. Robin J. Alexander, Towards Dialogic Teaching: Rethinking Classroom Talk (York, UK: Dialogos, 2008).

9. Paulo Freire, Pedagogy of the Oppressed, translated Myra Bergman Ramos (New York: Continuum, 2000).

10. Ibid., 73.

11. Henri Lefebvre, The Production of Space (Cambridge, MA: Blackwell, 2008).

12. Kris Gutierrez, Betsy Rymes, and Joanne Larson, "Script, Counterscript, and Underlife in the Classroom: James Brown versus Brown v. Board of Education," Harvard Educational Review 65, no. 3 (1995): 445-72.

13. Richard Arum and Josipa Roksa, Academically Adrift: Limited Learning on University Campuses (Chicago: University of Chicago Press, 2011), 3.

14. Elizabeth M Karle, "Invigorating the Academic Library Experience Creative Programming Ideas," University \& Research Libraries News 69, no. 3 (2008): 143; Jo Ann Reynolds and Laurel Rabschutz, "Studying for Exams Just Got More RelaxingAnimal-Assisted Activities at the University of Connecticut Library," University \& Undergraduate Libraries 18, no. 4 (October 1, 2011): 359-67, http://dx.doi.org/10.1080/10691316.2011.624 934; Allana Ahktar, "CSG Implements First Napping Station in UGLi," Michigan Daily, April 28, 2014, www.michigandaily.com/ news/csg-implements-first-napping-station-ugli; Elizabeth $\mathrm{M}$. Smigielski and Neal D. Nixon, "The Library as Finals Resting Place," Medical Reference Services Quarterly 23, no. 1 (March 1, 2004): 29-39, http://dx.doi.org/10.1300/J115v23n01_03.

15. Carlos Blanco et al., "Mental Health of University Students and Their Non-University-Attending Peers: Results from the National Epidemiologic Study on Alcohol and Related Conditions," Archives of General Psychiatry 65, no. 12 (December 2008): 1429-37, http://dx.doi.org/10.1001/archpsyc.65.12.1429.

16. James K Elmborg, "Libraries as the Spaces Between Us," Reference E User Services Quarterly 50, no. 4 (2011): 346.

17. "Learning Commons," University of Iowa Libraries, accessed August 4, 2014, www.lib.uiowa.edu/commons.

18. Frank Warren, PostSecret (blog), accessed August 4, 2014, http:// postsecret.com.

19. A project at Pennsylvania State University used a public display of anonymous postcards as a form of community healing after the sexual abuse scandal on their campus. See Jennifer Motter et al., "Post Silence: Visible Markers of Collective Remembrance, Awareness, and Action Toward Systemic Change," Cultural Studies_Critical Methodologies 12, no. 4 (August 1, 2012): 346-51, http://dx.doi.org/10.1177/1532708612446436.

20. Anna Poletti, "Intimate Economies: PostSecret and the Affect of Confession," Biography 34, no. 1 (2011): 31, http://dx.doi .org/10.1353/bio.2011.0000.

21. Although there were notes written in Chinese, Korean, and even Latin, this discussion is limited to the notes in English.

22. George D. Kuh et al., Student Success in University: Creating Conditions That Matter (San Francisco: Jossey-Bass, 2005), 195.

23. Elmborg, "Libraries as the Spaces Between Us," 347.

24. Kuh et al., Student Success in University: Creating Conditions That Matter, 315

25. Jeffrey R. Young, "Wikipedia Founder Discourages Academic Use of His Creation," Chronicle of Higher Education Blogs: Wired Campus, June 12, 2006, http://chronicle.com/blogs/wiredcampus/ wikipedia-founder-discourages-academic-use-of-his-creation/ 2305.

26. Cullen J Chandler and Alison S Gregory, "Sleeping with the Enemy: Wikipedia in the University Classroom," History Teacher 43 , no. 2 (2010): 247-57.
27. Heidi L. M. Jacobs, "Posing the Wikipedia 'Problem': Information Literacy and the Praxis of Problem-Posing in Library Instruction," in Critical Library Instruction: Theories and Methods, edited by Maria T. Accardi et al. (Duluth, MN: Library Juice Press, 2010), 179.

28. Academic history is here defined as what is studied at the university level, and published for a largely academic university audience. Public history is historical information curated and prepared often with the help of academic historians, but presented at a level fit for public consumption, such as in museums, books pitched at a general audience, or as historical documentaries.

29. Elmborg, "Libraries as the Spaces Between Us," 345.

30. Ibid.

31. Mikhail Bakhtin, Rabelais and His World, translated by Hélène Iswolsky (Cambridge, MA: MIT Press, 1968), 10.

32. Ibid.

33. danah boyd, It's Complicated: The Social Lives of Networked Teens (New Haven and London: Yale University Press, 2014): 181-82.

34. "Machu Picchu," Wikipedia, last modified March 21, 2014, http://en.wikipedia.org/w/index.php?title=Machu_Picchu \&oldid=600527145.

35. "Machu Picchu: Revision History,"Wikipedia, last modified March 21, 2014, http://en.wikipedia.org/w/index.php?title=Machu _Picchu\&oldid=600527145

36. Ibid.

37. Rob and Adamo, "Wikipedia Assignment Reflection Letter, March," 2014.

38. See for example Noam Cohen, "Wikipedia Ponders Its GenderSkewed Contributions," New York Times, January 30, 2011, www .nytimes.com/2011/01/31/business/media/31link.html?_r=0.

39. Adam, Gillian, Caitie, and Rebecca, "Wikipedia Assignment Reflection Letter," March 2014.

40. "Wikipedia: Please Do Not Bite the Newcomers," Wikipedia, accessed April 27, 2015, http://en.wikipedia.org/wiki/ Wikipedia:Please_do_not_bite_the_newcomers.

41. "Wikipedia: Please Bite the Newbies," Wikipedia, accessed April 27, 2015, http://en.wikipedia.org/wiki/Wikipedia:Please_bite_ the_newbies.

42. "Wikipedia: WikiBullying," Wikipedia, accessed April 27, 2015, http://en.wikipedia.org/wiki/Wikipedia:WikiBullying.

43. Ibid.

44. Ibid.

45. Calin, Sydney, Justin, and Emile, "Wikipedia Assignment Reflection Letter," March, 2014

46. "Welcome to Wikipedia," accessed April 27, 2015, http:// en.wikipedia.org/wiki/Main_Page

47. Calin, Sydney, Justin, and Emile, "Wikipedia Assignment Reflection Letter," March 2014.

48. Dustin and Lisa, "Wikipedia Assignment Reflection Letter," March 2014.

49. Dustin, "Wikipedia Assignment Reflection Letter," March, 2014.

50. Calin, Sydney, Justin, and Emile, "Wikipedia Assignment Reflection Letter," March 2014.

51. Bartholomae, "Inventing the University," 4-23.

52. Lefebvre, The Production of Space, 165.

53. Pauline R. Clance and Suzanne A Imes, "The Imposter Phenomenon in High Achieving Women: Dynamics and Therapeutic Intervention," Psychotherapy: Theory, Research \& Practice 15, no. 3 (1978): 241.

54. Mary Louise Pratt, "Arts of the Contact Zone," Profession 36 (1991): 37.

55. Dorothy C. Holland, William Lachiotte Jr., and Debra Skinner, Identity and Agency in Cultural Worlds (Cambridge, MA: Harvard University Press, 1998).

56. Holland et al., Identity and Agency, 53.

57. Ibid., 173. 